\title{
Breast Cancer Screening Tests Performance in Women Referred to Ardabil's Health Centers in 2016
}

\author{
Samira Shahbazzadegan ${ }^{1, *}$ \\ ${ }^{1}$ Department of Reproductive Health, Department of Midwifery, School of Nursing \\ and Midwifery, Ardabil University of Medical Sciences, Ardabil, Iran \\ * Corresponding author: Samira Shahbazzadegan, Department of Reproductive \\ Health, Department of Midwifery, School of Nursing and Midwifery, Ardabil \\ University of Medical Sciences, Ardabil, Iran. Tel: +98-9120697499, E-mail: \\ samirashahbazzadegan2000@yahoo.com
}

DOI: $10.21859 /$ mci-supp-77

\section{Keywords:}

Breast Cancer

Screening Tests

Breast Self-Examination

\begin{abstract}
Introduction: Breast cancer is one third of all kinds of cancers and the second reason of death in women. Prevention and screening can decrease affection and death rate. The aim of this study was to determine the breast cancer screening tests performance and affecting factors in women referred to Ardabil's Health Centers in 2016.

Material and Methods: In this descriptive-analytic study, 400 women referring to Ardabil's Health and Medical Centers were chosen by multistage sampling. The information was collected through the researcher-made questionnaire including two parts: Knowledge and Attitude questions and a form about demographical characteristics, family, social and economic factors, risk and women-midwifery factors. For analyzing the data, SPSS software version 16, and descriptive and deductive statistic tests were used.

Results: The percentage of screening tests including self-examination, clinical examination and mammography consequently were $7 \%, 5.7 \%$ and $5.1 \%$. There was significant relationship between breast self-examination and education $(\mathrm{P}=0.001)$, knowledge $(\mathrm{P}=$ 0.007 ) and attitude $(P=0.008)$. No significant difference was observed between insurance status and history of hormone therapy and breast cancer screening tests.

Conclusions: In regard to the low rate of breast cancer screening conducted and determining the affecting factors, the appropriate educational programs and interventional research are emphasized.
\end{abstract}

